\title{
PENGARUH PENYULUHAN KESEHATAN GIGI MENGGUNAKAN PERMAINAN ULAR TANGGA TERHADAP PENGETAHUAN SERTA KEBERSIHANGIGI DAN MULUT SISWA KELAS III SDI AL-AZHAR 33 TASIKMALAYA TAHUN 2017
}

\section{INFLUENCE OF DENTAL HEALTH CULTURE USING SNAKE TOOLS FOR KNOWLEDGE AND DENTAL CLEAN AND MOUTH STUDENTS OF CLASS III SDI AL-AZHAR 33 TASIKMALAYA 2017}

\author{
Anie Kristiani ${ }^{*}$ \\ ${ }^{1}$ Jurusan Keperawatan Gigi, Poltekkes Kemenkes Tasikmalaya \\ *aniekristiani@yahoo.com
}

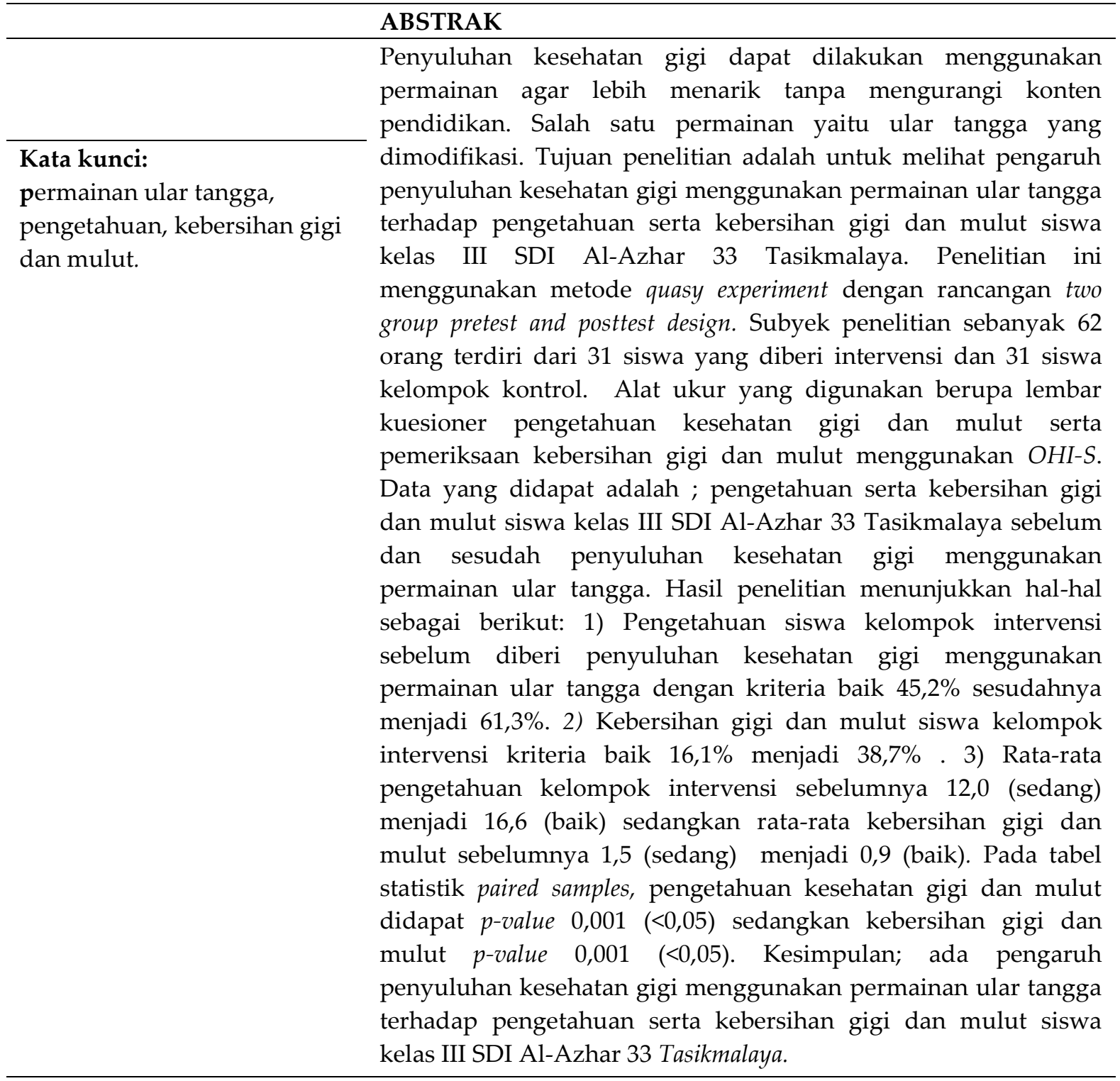


Key word:

snakes and ladders game, knowledge, Oral Hygiene.

\begin{abstract}
Dental counseling can be done with a game without decreasing educational content. One of the game is snakes and ladders game with modification. The purpose of this study is see the effect of dental counseling on knowledge and oral hygiene IIIrd grade students Al-Azhar Islamic 33 elmentary school. This research used quasy experiment with two group pretest and posttest design. The subject are 31 students from class with intervention and 31 control class. The measuring instrument used classifier for questioner paper and OHI-S paper to knowed that knowledge and the Oral Hygiene IIIrd grade students Al-Azhar Islamic 33 elementary school Tasikmalaya. Data which got is :1) knowledge students at intervention class both of before given dental counseling with snakes and ladders game, the result are : good from $45.2 \%$ ) become $61.3 \%$. 2) Oral Hygiene students at intervention class both of before good from $16.1 \%$ become $38.7 \%$. 3)Mean from knowledge students at intervention class before 12.0 (less) to 16.6 (good) and mean Oral Hygiene students at intervention class before 1.5 (fair) to 0.8(good). At paired samples statistic table, to knowledge class intervention and control class pvalue $0.001(<0.05)$. and Oral Hygiene class intervention and control class p-value $0.001 \quad(<00.5)$. The impact of dental counseling with snakes and ladders game toward the knowledge and Oral Hygiene IIIrd grade students Al-Azhar Islamic 33 elementary School Tasikmalaya.
\end{abstract}

\title{
PENDAHULUAN
}

Data RISKESDAS (2013) menyatakan persentase masyarakat yang mempunyai masalah kesehatan gigi dan mulut sebesar $25,9 \%$, persentase ini mengalami peningkatan jika dibandingkan dengan data RISKESDAS pada tahun 2007 yaitu 23,2\% menjadi 25,9\%. Survey World Health Organization (WHO) tahun 2007, menambahkan bahwa pada anak-anak Indonesia usia 6 tahun telah mengalami karies sebanyak 20\%, berlanjut mengalami peningkatan yang luar biasa terjadi pada anak usia 12 tahun yaitu $90 \%$.

Media pembelajaran yang dapat melibatkan siswa dalam proses pembelajaran yang aktif dan menyenangkan belum banyak dijumpai di sekolah. Salah satu upaya menciptakan situasi belajar yang aktif dan menyenangkan untuk siswa sekolah dasar adalah dengan mengajak siswa bermain sambil belajar. Dalam bermain juga terjadi proses belajar, sehingga dari bermain ini siswa akan memperoleh pengalaman belajar yang menyenangkan (Purwanto, 2010). Pendapat Sadiman, dkk., (2011) tentang deskripsi permainan yaitu: "Permainan (games) adalah setiap kontes antara para pemain yang berinteraksi satu sama lain dengan mengikuti aturan-aturan tertentu untuk mencapai tujuan-tujuan tertentu pula". Permainan adalah modal awal bagi pembinaan awal kecerdasan dan mental-emosional anak, sehingga cara dan pola bermain yang diterapkan dalam pembelajaran akan memiliki efek positif bagi pertumbuhan kecerdasan dan emosional anak. Permainan dapat membantu suasana lingkungan belajar menjadi senang, bahagia serta dapat menemukan sendiri konsep materi yang sedang dipelajari. Melalui bermain, banyak kemampuan/keterampilan dapat dipraktekkan secara berulang-ulang sehingga bisa dikuasai dengan baik. Permainan ular tangga dapat dijadikan sebagai media pembelajaran yang menyenangkan bagi siswa. 
Siswa akan cenderung tertarik mengikuti proses pembelajaran. Dalam hal ini, guru berperan sebagai fasilitator bagi siswa. Siswa yang aktif dalam permainan ular tangga dapat menemukan sendiri konsep materi yang sedang dipelajari.

Berdasarkan teori perkembangan kognitif dari Piaget anak usia 6-12 tahun ini diberikan adalah stimulus melalui permainan. Jenis permainan yang dapat digunakan salah satunya adalah permainan ular tangga. Permainan ini dipilih karena anak tidak perlu mengeluarkan banyak energi ketika memainkannya. Permainan ini mengandung beberapa aspek yang mengajarkan kepada anak mengenai moral dan etika tentang kebaikan dan keburukan. (Augustyn, 2004).

Hasil penelitian Afif Hamdalah menyatakan efektivitas media permainan ular tangga lebih tinggi daripada media cerita bergambar dalam mempersepsikan pengetahuan, sikap dan praktek tentang kesehatan gigi dan mulut. (Hamdalah, 2011). Penelitian Ani Labibah dkk memperlihatkan terdapat pengaruh permainan ular tangga modifikasi terhadap peningkatan pengetahuan tentang kesehatan gigi dan mulut pada anak (Labibah dkk, 2015).

Pengertian Oral Hygiene index Simplipied (OHI-S) merupakan suatu Index yang digunakan untuk mengukur kebersihan gigi dan mulut (score) adanya plak dan karang gigi yang menempel pada permukaan gigi atau yang didapat dari hasil penjumlahan Debris Index (Be Kien Nio, 1987). Pemeriksaan OHI-S adalah pemeriksaan gigi dan mulut dengan menjumlahkan, hasil Debris Index (DI) dan Calculus Index (CI). Debris Index adalah score (nilai) yang terjadi karena sisa makanan yang melekat pada gigi penentu, Calculus Index adalah score (nilai) dari endapan keras (karang gigi) terjadi karena debris yang mengalami pengapuran yang melekat pada gigi penentu. Pemeriksaan $O H I-S$ dengan tujuan untuk mengumpulkan data kebersihan gigi dan mulut sasaran dan merencanakan tindakan promotif-preventif (Green dan Vermillion, 1964, cit. Be Kien Nio, 1987). Hasil pemeriksaan awal di SDI Al-Azhar 33 Tasikmalaya pada bulan Mei 2016, ditemukan prevalensi karies sebesar 82,4\% artinya ditemukan 75 murid yang menderita karies dari 91 murid yang diperiksa

\section{METODE}

Alat dan bahan yang digunakan adalah sonde, pinset, kaca mulut, disclosing solution, alkohol 70\%, benecide, aquadest, kapas, gelas kumur, hand schoen, sterilisator kimia, handuk, slaberche, baki, ember, boneka-boneka tangan, panggung sandiwara boneka, laptop, speaker, alat tulis, kuesioner pengetahuan kesehatan gigi dan mulut, formulir pemeriksaan $O H I-S$. Metode yang digunakan adalah quasy experiment dengan rancangan two group pretest and posttest design. Subyek penelitian sebanyak 31 siswa sebagai kelas intervensi dan 31 siswa kelas kontrol. Alat ukur yang digunakan berupa kuesioner pengetahuan dan $O H I-S$. kelompok intervensi sebelumnya diminta mengisi kuesioner untuk mengukur pengetahuan kesehatan gigi dan mulut lalu diperiksa intra oralnya untuk mendapatkan nilai $O H I-S$. Kelompok intervensi diberi penyuluhan kesehatan gigi menggunakan permainan ular tangga selama durasi 60 menit sebanyak tiga kali selama 3 minggu berturut-turut. Setelah itu diberi kuesioner yang sama untuk mengukur pengetahuan kesehatan gigi dan dilakukan pengukuran $O H I-S$ akhir.

\section{HASIL DAN PEMBAHASAN}

Siswa kelas III SDI Al-Azhar 33 Tasikmalaya sebanyak 31 orang terdiri dari 16 $(51,6 \%)$ laki-laki dan $15(48,4 \%)$ perempuan. Sebanyak 64,5\% responden berumur 8 tahun. 
Tabel 1 : Distribusi frekwensi Pengetahuan Responden Sebelum dan Sesudah diberi Perlakuan.

\begin{tabular}{|c|c|c|c|c|c|}
\hline \multirow{2}{*}{ No. } & Kriteria & \multicolumn{2}{|c|}{ Sebelum } & \multicolumn{2}{c|}{ Sesudah } \\
\cline { 3 - 6 } & Pengetahuan & N & \% & N & \% \\
\hline 1. & Baik & 14 & 45,2 & 19 & 61,3 \\
\hline 2. & Sedang & 16 & 51,6 & 12 & 38,7 \\
\hline 3. & Buruk & 1 & 3,2 & 0 & 0 \\
\hline & Jumlah & 31 & 100 & 31 & 100 \\
\hline
\end{tabular}

Tabel 1 memperlihatkan adanya peningkatan pengetahuan responden kelompok intervensi sebelum penyuluhan kesehatan gigi menggunakan permainan ular tangga kriteria baik 45,2\% sesudahnya menjadi $61,3 \%$.

\section{Tabel 2 : Perbedaan Rata-rata Pengetahuan Kelompok Intervensi dan rata-rata} Kelompok Kontrol Sebelum dan Sesudah perlakuan.

\begin{tabular}{|c|c|c|c|c|c|}
\hline No. & $\begin{array}{c}\text { Rata-rata } \\
\text { Pengetahuan }\end{array}$ & Sebelum & Sesudah & Perubahan & $\begin{array}{c}\boldsymbol{p} \text { - } \\
\text { value }\end{array}$ \\
\hline 1. & $\begin{array}{c}\text { Kelompok } \\
\text { intervensi }\end{array}$ & 12,0 & 16,6 & 4,6 & 0,0001 \\
\hline
\end{tabular}

Tabel 2. Menunjukkan rata-rata pengetahuan kelompok intervensi sebelumnya 12,0 (kriteria sedang) menjadi 16,6 (kriteria baik) maka selisihnya adalah 4,6. Hasil uji paired samples test perbandingan pengetahuan responden pada kelompok intervensi menunjukkan p-value $0,001(<0,05)$ sehingga dapat dikatakan bermakna.

\section{Tabel 3 : Distribusi frekwensi Kebersihan Gigi dan Mulut Kelompok Intervensi Sebelum dan Sesudah Diberi Perlakuan.}

\begin{tabular}{|c|c|c|c|c|c|}
\hline \multirow{2}{*}{ No. } & \multirow{2}{*}{$\begin{array}{c}\text { Kriteria } \\
\text { OHI-S }\end{array}$} & \multicolumn{2}{|c|}{ Sebelum } & \multicolumn{2}{c|}{ Sesudah } \\
\cline { 3 - 6 } & Baik & 5 & 16,1 & 12 & 38,7 \\
\hline 1. & Sedang & 26 & 83,9 & 19 & 61,3 \\
\hline 2. & Buruk & 0 & 0 & 0 & 0 \\
\hline 3. & Jumlah & 31 & 100 & 31 & 100 \\
\hline &
\end{tabular}

Tabel 3 memperlihatkan adanya peningkatan kebersihan gigi dan mulut kelompok intervensi sebelum penyuluhan kesehatan gigi menggunakan permainan ular tangga kriteria baik $16,1 \%$ sesudahnya menjadi $38,7 \%$. 
Tabel 4 : Perbedaan Rata-rata Kebersihan Gigi dan Mulut Kelompok Intervensi Kelompok Kontrol Sebelum dan Sesudah Perlakuan.

\begin{tabular}{|c|c|c|c|c|c|}
\hline No. & Rata-rata OHI- & Sebelum & Sesudah & Perubahan & $\boldsymbol{p}$ - \\
& $\boldsymbol{S}$ & 1,5 & 0,9 & 0,6 & 0,0001 \\
\hline 1. & $\begin{array}{l}\text { Kelompok } \\
\text { intervensi }\end{array}$ & & & \\
\hline
\end{tabular}

Tabel 4. Menunjukkan rata-rata kebersihan gigi dan mulut kelompok intervensi sebelum penyuluhan kesehatan gigi menggunakan permainan ular tangga 1,5 (kriteria sedang) menjadi 0,9 (kriteria baik) maka selisihnya adalah 0,6. Hasil uji paired samples test perbandingan kebersihan gigi dan mulut responden pada kelompok intervensi menunjukkan $p$-value 0,001 $(<0,05)$ sehingga dapat dikatakan bermakna.

Pengetahuan siswa kelas III SDI Al-Azhar 33 Tasikmalaya sebelum penyuluhan kesehatan gigi menggunakan permainan ular tangga dengan kriteria baik 45,2\% menjadi 61,3\%. Rata-rata pengetahuan sebelumnya 12,0 (kriteria sedang) menjadi 16,6 (kriteria baik) maka selisihnya adalah 4,6. Kebersihan gigi dan Mulut siswa kelas III SDI Al-Azhar 33 Tasikmalaya sebelum penyuluhan kesehatan gigi menggunakan permainan ular tangga kriteria baik $16,1 \%$ menjadi $38,7 \%$. Rata-rata kebersihan gigi dan mulut sebelumnya 1,5 (kriteria sedang) menjadi 0,9 (kriteria baik) maka selisihnya adalah 0,6.

Berdasarkan hasil penelitian bahwa penyuluhan kesehatan gigi menggunakan permainan ular tangga berpengaruh dalam meningkatkan pengetahuan kesehatan gigi dan mulut pada siswa kelas III SDI Al-Azhar 33 Tasikmalaya. Hal ini ditunjukkan dari hasil uji Paired Sample Test diperoleh nilai $p=0,001$ yang berarti terdapat perbedaan pengetahuan kesehatan gigi dan mulut yang bermakna sebelum dan sesudah dilakukan intervensi. Demikian pula penyuluhan kesehatan gigi menggunakan permainan ular tangga juga berpengaruh dalam meningkatkan kebersihan gigi dan mulut pada siswa kelas III Al-Azhar 33 Tasikmalaya. Hal ini ditunjukkan dari hasil uji Paired Sample Test diperoleh nilai $p=$ 0,001 yang berarti terdapat perbedaan kebersihan gigi dan mulut yang bermakna sebelum dan sesudah dilakukan intervensi.

Penggunaan permainan ular tangga dalam pendidikan kesehatan gigi ini membuat siswa lebih aktif dan antusias dalam mengikuti penyuluhan, hal tersebut dibuktikan bahwa sebelum permainan dimulai siswa diminta untuk memperhatikan materi kesehatan gigi yang diberikan sebelumnya menggunakan metode ceramah. Penggunaan permainan ular tangga pada penyuluhan kesehatn gigi mewujudkan adanya perbedaan cara petugas kesehatan memberi penyuluhan dengan adanya variasi media pembelajaran untuk menerapkan pembelajaran yang lebih menyenangkan dan menimbulkan minat belajar pada siswa, sehingga membuat siswa lebih aktif, antusias, dan tidak bosan dalam mengikuti penyuluhan. Selain itu siswa terlihat bersemangat dalam menyimak materi, hal itu membuktikan bahwa penggunaan permainan ular tangga dalam penyuluhan dapat meningkatkan pengetahuan kesehatan gigi dan mulut serta dapat meningkatkan kebersihan gigi dan mulutnya. 


\section{KESIMPULAN}

Pengetahuan kesehatan gigi sebelum penyuluhan menggunakan permainan ular tangga dengan kriteria baik meningkat dari $45,2 \%$ menjadi $61,3 \%$. Rata-rata pengetahuan kesehatan gigi sebelum penyuluhan 12,0 sesudahnya menjadi 16,6 .

1. Kebersihan gigi dan mulut sebelum penyuluhan menggunakan permainan ular tangga dengan kriteria baik 16,1\% meningkat menjadi 38,7\%. Rata-rata kebersihan gigi dan mulut sebelum penyuluhan 1,5 (kriteria sedang) sesudahnya menjadi 0,9 (kriteria baik).

2. Ada pengaruh penyuluhan kesehatan gigi menggunakan pernmainan ular tangga terhadap pengetahuan serta kebersihan gigi dan mulut siswa kelas III SDI Al-Azhar 33 Tasikmalaya, dilihat dari $p$-value terhadap pengetahuan $=0,001(<0,05)$ dan terhadap kebersihan gigi dan mulut=0,001 $(<0,05)$.

\section{DAFTAR PUSTAKA}

Badudu J.S., Sutan Mohammad Zain, 1994, Kamus Umum Bahasa Indonesia, Pustaka Sinar Harapan: Jakarta.

Be Kien Nio., 1989, Preventive Dentistry II, YKGI. Bandung.

Departemen Kesehatan R.I., 1995, Tata Cara Kerja Pelayanan Asuhan Kesehatan Gigi dan Mulut, Direktorat Kesehatan Gigi, Jakarta. 2009, a. Rencana Pembangunan Jangka Panjang Bidang Kesehatan (RPJP-K), Depkes RI: Jakarta. , 2009, b. UU RI No.36 Tahun 2009 Tentang Kesehatan dan Penjelasannya, Pusat Komunikasi Publik: Jakarta.

Desmita. (2011). Psikologi Perkembangan Peserta Didik. Bandung: PT. Remaja Desmita. (2011). Psikologi Perkembangan Peserta Didik. Bandung: PT. Remaja Rosdakarya.

Ghofur A. 2012, Buku Pintar Kesehatan Gigi dan Mulut, Mitra Buku: Yogyakarta.

Hamdalah A. 2013, Jurnal Promkes, Vol 1 No 2 Desember 2013, Fakultas Kesehatan Masyarakat Universitas Jember : Jember.

Herijulianti E., Tati Svasti Indriani, Sri Artini, 2002,Pendidikan Kesehatan Gigi. Penerbit Buku Kedokteran EGC: Jakarta.

Hongini S.Y., Mac Aditiawarman, 2012, Kesehatan Gigi dan Mulut, Pustaka Reka Cipta: Bandung.

Houwink, B.,1993, Ilmu Kedokteran Gigi Pencegahan, Gajah Mada Universitas Press, Fakultas Kedokteran Gigi UGM, Yogyakarta.

Ismail, A. (2006). Education Games, Menjadi Cerdas dan Ceria dengan Permainan Edukatif. Yogyakarta: Pilar Media.

Kementerian Kesehatan RI, 2013, Riset Kesehatan Dasar (Riskesdas) 2013, Balitbangkes: Jakarta.

2014, Profil Kesehatan Indonesia Tahun 2013, Kemenkes RI: Jakarta.

Labibah A, Nurhapsari A, Mujayanto R (2015), Jurnal Medali Vol 2, no 1 Media Dental Intelektual, Fakultas Kedokteran Gigi Universitas Islam Sultan Agung.

Martariwansyah, 2008, Gigiku Kuat, Mulutku Sehat, Hayati Qualita: Bandung.

Maulani C., Jubilee Enterprise, 2005, Kiat Merawat Gigi Anak : Panduan Orang Tua dalam Merawat dan Menjaga Kesehatan Gigi bagi Anak-anaknya, PT Elex Media Komputindo: Jakarta.

Mulyatiningsih, E. (2012). Metode Penelitian Terapan Bidang Pendidikan. Yogyakarta: Alfabeta. 
Mumpuni Y., Erlita Pratiwi, 2013, 45 Masalah dan Solusi Penyakit Gigi dan Mulut. Rapha Publishing: Yogyakarta.

Notoatmodjo S, 2010, Ilmu Perilaku Kesehatan, PT Rineka Cipta: Jakarta.

Nugroho, A.P. (2013). Pengembangan Media Pembelajaran Fisika Menggunakan Permainan Ular Tangga Ditinjau dari Motivasi Belajar Siswa Kelas VII Materi Gaya. Skripsi, Universitas Sebelas Maret, Surakarta.

Pratiwi, D., 2007, Merawat Gigi Sehari-hari, PT. Kompas, Jakarta.

Purwanto, N. (2010). Psikologi Pendidikan. Bandung : PT Remaja Rosdakarya.

Rusman. (2012). Belajar dan Pembelajaran Berbasis Komputer. Bandung: Alfabeta

Sadiman, A.S., Rahardjo, R., Haryono, A., \& Rahardjito. (2011). Media Pendidikan: Pengertian, Pengembangan, dan Pemanfaatannya. Jakarta: PT. Raja Grafindo Persada.

Sastroasmoro S., Sofyan Ismael, 2011, Dasar-dasar Metodologi Penelitian Klinis. CV.Agung Seto: Jakarta.

Sugiyono, 2006, Metode Penelitian Pendidikan (Pendekatan Kuantitatif, Kualitatif dan $R \& D)$, Alfabeta: Bandung. 2010, Metode Penelitian Pendidikan. Bandung: Alfabeta.

Sumantoro, J. T. (2013). Pengembangan Perangkat Pembelajaran Metode Pembelajaran Kooperatif Tipe Teams Games Tournament (TGT) Menggunakan Media Permainan Ular Tangga Untuk Meningkatkan Hasil Belajar Siswa. Jurnal Pendidikan Teknik Elektro. Vol.2 No. 2.

Tim Puslijaktinov. (2008). Metode Penelitian Pengembangan. Jakarta: Departemen Pendidikan Nasional.

Widyanti, S., 2005, Pengantar Ilmu Kedokteran Gigi Pencegahan, Medika Fakultas Kedokteran UGM, Yogyakarta. 